\title{
Effect of intraband variability on stable isotope and density time series obtained from banded corals
}

\author{
S Chakraborty ${ }^{1}$, R RAmesh ${ }^{1, *}$ and J M LOUGH ${ }^{2}$ \\ ${ }^{1}$ Physical Research Laboratory, Ahmedabad 380 009, India. \\ ${ }^{2}$ Australian Institute of Marine Science, Townsville, Queensland, Australia. \\ *email: ramesh@prl.ernet.in
}

Density, $\delta^{18} \mathrm{O}$ and $\delta^{13} \mathrm{C}$ were measured along two tracks, one close to the central growth axis and the other, $\sim 20^{\circ}$ off the axis, in a coral (Porites lutea) collected from the Stanley Reef, Central Great Barrier Reef, Australia. The $\delta^{18} \mathrm{O}$ variations in the coral are well correlated with sea surface temperature changes. The common variances between the two tracks were about $60 \%$ in the $\delta^{18} \mathrm{O}, \delta^{13} \mathrm{C}$, and the skeletal density variations. Part of the noise $(40 \%)$ could be due to the difficulty of sampling exactly time contemporaneous parts of each band along the two tracks and part of it could be due to genuine intraband variability. In spite of the intraband variability, the time series obtained from the two tracks are similar, indicating that the dominant causative factor for the isotopic variations is external, i.e., the environmental conditions that prevail during the growth of the coral; density band formation does not appear to be directly controlled by the sea surface temperature.

\section{Introduction}

One of the aims of the PAst Global ChangES (PAGES) project under the International Geosphere Biosphere Programme (IGBP) is the reconstruction of the climatic history of the earth during the last 2000 years with a high resolution of one year or less (Eddy 1992). Such high resolution proxy climatic records are provided by ring width, ring density and stable isotope ratios of carbon, hydrogen and oxygen of tree rings on land (Fritts 1976; Hughes et al 1982; Yapp and Epstein 1982; Ramesh et al 1985; 1986) and by band density and stable oxygen isotope ratios of massive corals in the sea (Fairbanks and Dodge 1979; Patzold 1984; Druffel 1985; McConnaughey 1989; Cole and Fairbanks 1990; Lough and Barnes 1990; Aharon 1991; Chakraborty and Ramesh 1993; 1997; 1999; Charles et al 1997). If the time series of these proxy climatic indicators is entirely governed by the ambient climate, then there should not be any significant variations of these parameters within a single annual ring (tree) or band (coral). However, both in trees and corals, there exist significant intra-ring and intraband variability in isotope ratios and other climate indices. This shows that at least part of the variance in a time series obtained from trees and corals is due to internal, growth related effects. Therefore it is important to assess how much "noise" is introduced into the "signal" because of this intra-ring and intraband variability. Such an exercise has already been carried out for tree rings (Ramesh et al 1985). Here we repeat this exercise for corals, because a systematic study of the effect of the intraband variability for corals does not exist except for the oxygen isotope measurements of McConnaughey (1989) in a single band of a coral showing significant intraband $\delta^{18} \mathrm{O}$ variability of $1.2 \%$ (cf. experimental precision of $\pm 0.05 \%$ ). Our exercise would lead to an estimate of the signal/noise ratio which will enable evaluation of how much of the variance in the coral based time series is controlled by external (climatic) influence and how much is controlled by internal (growth-related) effects.

Keywords. Carbon isotope; oxygen isotope; SST; climate; coral; Great Barrier Reef. 
In addition, we also address the question of the cause of the density band formation in corals. Highsmith (1979) and Weber et al (1975) concluded that the sea surface temperature (SST) controls the density band formation in corals, while Buddemeier (1974) and Wellington and Glynn (1983) have attributed the seasonally varying growth rate to be the cause of the annual banding. One might probably argue that the variation in SST controls the growth rate and thereby affects the band formation. However, it has been seen that the same species of corals form high or low density bands in summer/winter in different geographical locations (Chivas et al 1983; Barnes and Lough 1989). Therefore it appears that the availability of sunlight and nutrients rather than SST controls the growth rate. It is possible to distinguish between the Highsmith-Weber hypothesis and Buddemier-WellingtonGlynn hypothesis by measuring the stable carbon and oxygen isotope ratios in the same points of the coral band where density has been measured; if the density variation correlates with $\delta^{18} \mathrm{O}$, which depends mostly on SST (and to a small extent on the salinity or $\delta^{18} \mathrm{O}$ of sea water), then the former hypothesis is valid. On the other hand, if density variation correlates with $\delta^{13} \mathrm{C}$, which depends on growth rate (McConnaughey 1989) the latter hypothesis is valid.

Thus in this paper, we address the following two questions:

- effect of intra-band variability on the coral time series and

- the causal mechanism for density band formation in corals.

We have chosen the genus Porites for this study because:

- they produce fairly well defined annual density bands clearly identifiable in an X-ray picture;

- their growth rate is relatively higher (1 to $2 \mathrm{~cm} / \mathrm{yr})$, and their polyp size is smaller $(\sim 1 \mathrm{~mm})$ than most massive corals;

- they have a wide geographical distribution and thus offer a good spatial coverage and

- their oxygen isotope ratios have been shown to be related to SST (Weber and Woodhead 1972; Druffel 1985 and McConnaughey 1989).

We have made density, $\delta^{18} \mathrm{O}$ and $\delta^{13} \mathrm{C}$ measurements along two tracks of a Porites lutea collected from shallow water (few metres at low tide) depth in the Stanley Reef $\left(19^{\circ} 15^{\prime} \mathrm{S}, 148^{\circ} 07^{\prime} \mathrm{E}\right)$, Australia in December, 1986. To our knowledge there is no earlier study in which stable isotopes have been measured in the same coral subsamples where density measurements were made.

In general the $\delta^{18} \mathrm{O}$ of coralline $\mathrm{CaCO}_{3}$ depends on the SST and the $\delta^{18} \mathrm{O}$ of sea water. As the latter is not a routinely measured oceanographic parameter, one uses the linear relationship between $\delta^{18} \mathrm{O}$ of the sea

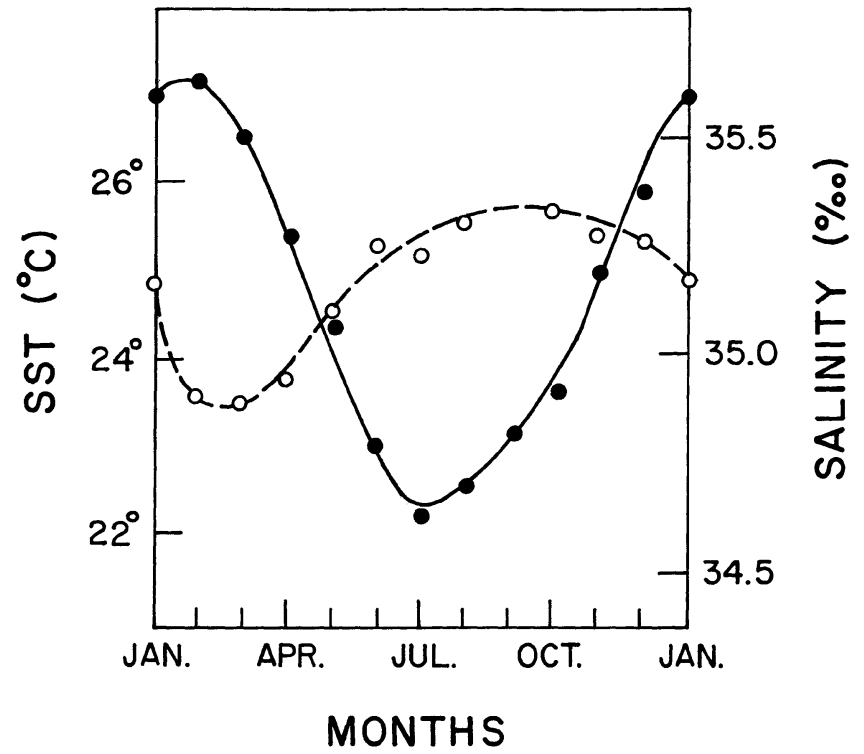

Figure 1. Annual cycle of sea surface temperature (filled circle) and salinity (open circle) in the Stanley Reef, Australia. (Data from Pickard et al 1977).

water and its salinity to calculate its effect on the $\delta^{18} \mathrm{O}$ of the coralline $\mathrm{CaCO}_{3}$. For south Pacific, where our coral comes from the coefficient for $\delta^{18} \mathrm{O}$-salinity variation is $0.65 \%$ per \%o (Craig and Gordon 1965). Figure 1 shows the annual cycle in the SST and salinity of the coral site (data from Pickard et al 1977). SST ranges from a minimum of $22.5 \pm 0.5^{\circ}$ in winter (July) to a maximum of $27.0 \pm 1.2^{\circ} \mathrm{C}$ in summer (January). Salinity varies from 34.9 to $35.3 \%$, with a range that corresponds to $0.26 \%$ in $\delta^{18} \mathrm{O}$ of the sea water, using the above slope. Thus the salinity induced $\delta^{18} \mathrm{O}$ variation in the coral $(0.26 \%)$ is smaller than that induced by SST change $(1.1 \pm 0.27 \%$, assuming a temperature coefficient of $\left.-0.2 \%{ }^{\circ} \mathrm{C}^{-1}\right)$. Therefore, for the purpose of this paper, we neglect the salinity influence on the coralline $\delta^{18} \mathrm{O}$, even though it is quite significant.

\section{Experimental methods}

A $1 \mathrm{~cm}$ thick slice of the coral was prepared and an Xray picture was taken (figure 2). Dates were assigned to the bands by counting from the top, which was assigned the year of collection. Density was measured along three tracks shown in figure 2 using gamma densitometry. The procedure is described in detail by Barnes and Lough (1989) and Lough and Barnes (1990). For stable isotope analysis we choose two tracks one close to the central growth axis (track-1) and the other $\sim 20^{\circ}$ off the axis (track-2). We chose not to analyze stable isotope ratios in the third track as it caused sampling problems due to reduced band width. The mean growth rates for track- 1 and track- 2 are 0.97 and $0.91 \mathrm{~mm} /$ month respectively. The word "growth rate" in coral literature has been replaced 


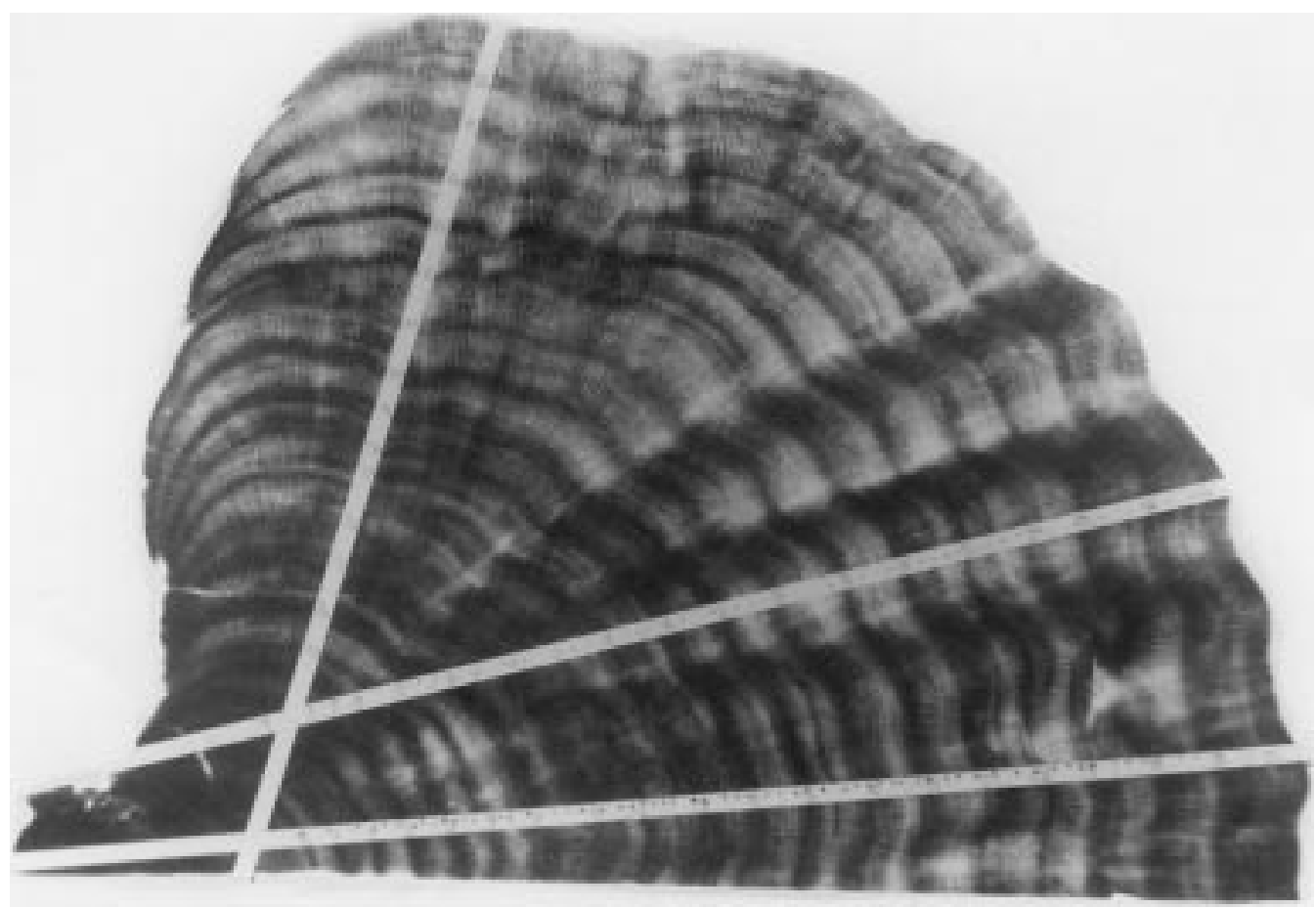

Figure 2. X ray positive of the Porites coral used for this study. Tracks 1 and 2 along which measurements have been carried out are marked (bottom strip: track 1; middle strip: track 2).

by appropriate terms like "extension rate" or "calcification rate" since they show a strong positive correlation (correlation coefficients of 0.98 and 0.93 for track-1 and 2 respectively, figure 3 ). Such a positive correlation between the calcification and extension rates was also shown by Scoffin et al (1992) in a P. lutea coral at Kotti, South Thailand. Stable isotope measurements were made on 3 to 5

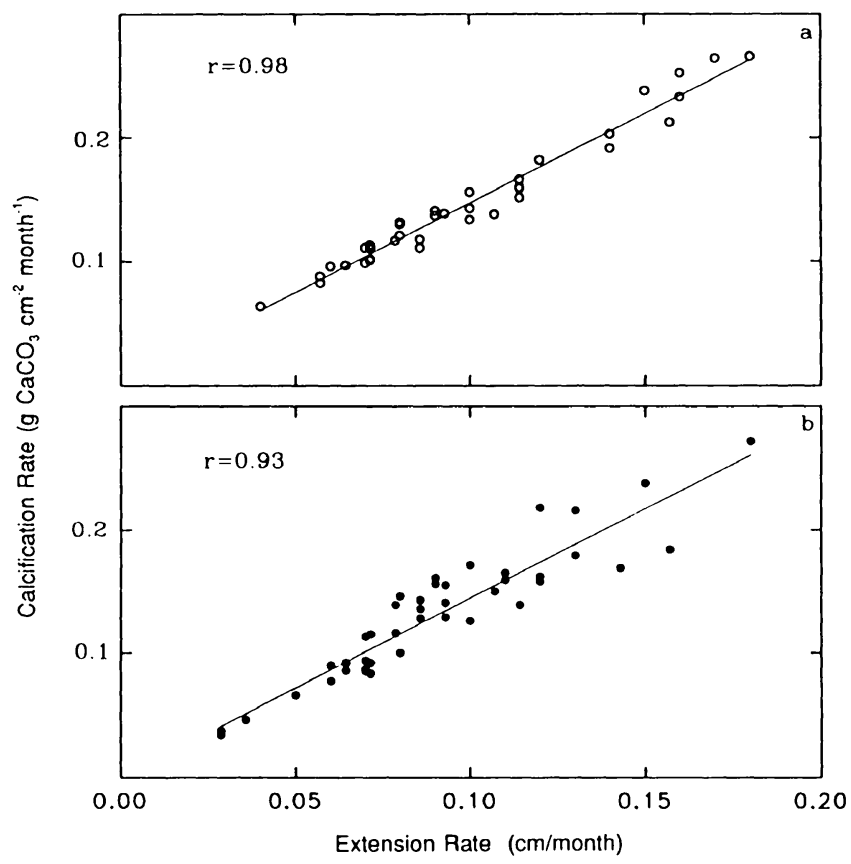

Figure 3. Linear correlation between calcification rate and skeletal extension rate along the two tracks, (a) track 1; (b) track 2 . samples in a year, including the highest and lowest density points along the two tracks following standard techniques (for details see Chakraborty and Ramesh 1992; 1997). The X-ray positive was used as a guide to select these subsamples for isotopic measurements.

\section{Results and discussion}

\subsection{Oxygen isotopes and SST}

Before proceeding to answer the two questions addressed earlier, we first show that the $\delta^{18} \mathrm{O}$ of this coral is indeed correlated with SST. The monthly averaged SST data were available from the Comprehensive Ocean Atmospheric Data Set (COADS). The maxima and minima in the $\delta^{18} \mathrm{O}$ time series correspond to July and January respectively. Assuming a linear growth rate for summer and a different (linear) growth rate for winter, the $\delta^{18} \mathrm{O}$ values other than the maxima and minima were approximately assigned a month. A linear regression was then carried out between $\delta^{18} \mathrm{O}$ and SST.

For track-1

$$
\begin{aligned}
\delta^{18} \mathrm{O}= & (-0.116 \pm 0.024) \mathrm{SST}-(1.96 \pm 0.06) \\
& (n=46, r=-0.885)
\end{aligned}
$$

For track-2

$$
\begin{aligned}
\delta^{18} \mathrm{O}= & (-0.154 \pm 0.013) \mathrm{SST}-(1.14 \pm 0.03) \\
& (n=46, r=-0.64)
\end{aligned}
$$

both correlation coefficients $(r)$ are significant at 0.01 level (Student's t test). These equations are similar to 
the one reported for the same species from a nearby reef (Matsumoto 1993), using data from a single track.

$$
\delta^{18} \mathrm{O}=(-0.131) \mathrm{SST}-1.35(r=-0.907) .
$$

The coral Porites lobata from Galapagos $\left(1^{\circ} \mathrm{S}\right.$, $90^{\circ} 20^{\prime} \mathrm{W}$ ) showed a temperature coefficient of $-0.21 \%{ }^{\circ} \mathrm{C}^{-1}$ (McConnaughey 1989). Therefore it appears that there may be significant differences in the temperature coefficients of different species of the same genus, growing in different geographical regions. Nevertheless, our result shows that $\delta^{18} \mathrm{O}$ of the coral analyzed by us is indeed related to SST (and may be to a smaller extent to salinity, as discussed earlier) and as we move away from the central axis, the correlation coefficient decreases significantly, probably indicating the effect of intra-band $\delta^{18} \mathrm{O}$ variability. As the sampling clearly captures the maxima and minima in $\delta^{18} \mathrm{O}$, we get a reasonably good correlation for track-1. This also ensures that we have not grossly missed the maxima/minima by sampling 3 to 5 points in a band. Had we not used the density curve for sub-sampling the bands, we could have missed the seasonal cycles by sampling only 3 to 5 points in a band.

\subsection{Oxygen, carbon isotopes and density}

The density, $\delta^{18} \mathrm{O}$ and $\delta^{13} \mathrm{C}$ variations along track-1 are shown in figure 4 and those for track- 2 are shown

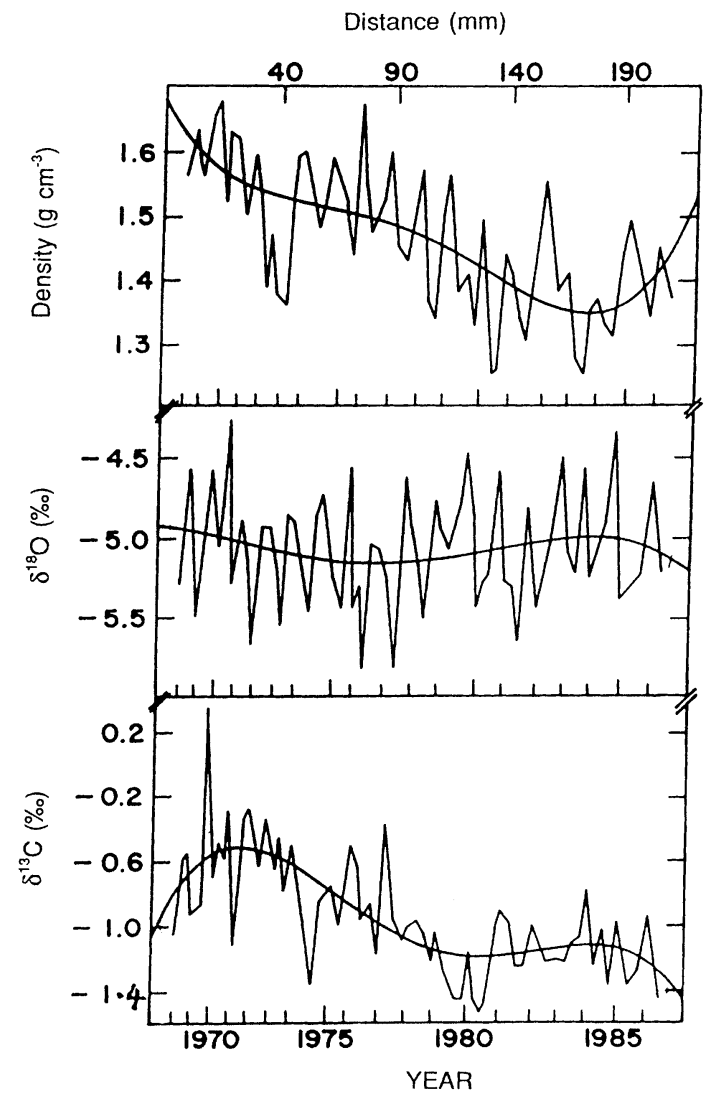

Figure 4. $\quad \delta^{18} \mathrm{O}, \delta^{13} \mathrm{C}$ and density variations along track 1. Smooth lines indicate trends (4th order polynomial fit).

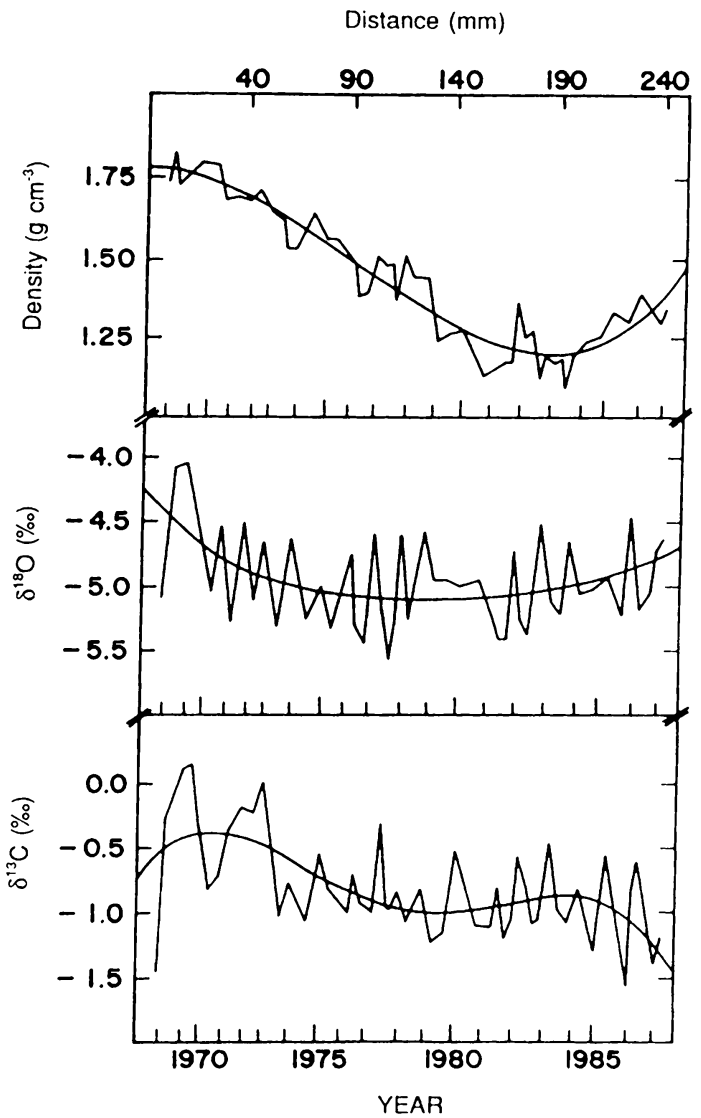

Figure 5. $\quad \delta^{18} \mathrm{O}, \quad \delta^{13} \mathrm{C}$ and density variations along track 2 . Smooth lines indicate trends (4th order polynomial fit).

in figure 5. Smooth curves in these figures indicate trends (obtained by fitting a fourth order polynomial). Though the density was measured at much closer intervals $(0.0254 \mathrm{~cm})$ those values corresponding to the points sampled for isotopic analysis alone are shown in these figures. In neither of the tracks the $\delta^{18} \mathrm{O}$ shows any significant trend, whereas the $\delta^{13} \mathrm{C}$ shows a decreasing trend in both the tracks. The most likely reason for this decreasing trend is the growth-raterelated carbon isotopic fractionation. This coral shows a progressive increase in growth rate ( $\sim 7$ to $15 \mathrm{~mm} / \mathrm{yr}$ in track- 1 and $\sim 8$ to $15 \mathrm{~mm} / \mathrm{yr}$ in track-2) during its life span, which results in a decreasing trend in $\delta^{13} \mathrm{C}$ (McConnaughey 1989). The other possible reason, viz., the changes in surface water $\delta^{13} \mathrm{C}$ due to the uptake of fossil fuel $\mathrm{CO}_{2}$, which is about $-0.4 \%$ in the Pacific (Quay et al 1992) cannot completely account such a large change $(-1 \%$ ).

The mean $\delta^{18} \mathrm{O}$ of track- 1 is $-5.07 \pm 0.35 \%$, and that of track- 2 is $-4.97 \pm 0.36 \%$. These values are not significantly different at the $5 \%$ significance level (Student's t-test for the difference between two means). Similarly, the mean $\delta^{13} \mathrm{C}$ values are $-0.95 \pm 0.38 \%$ or for track- 1 and $-0.83 \pm 0.39 \%$, again in good agreement. The mean densities for the two tracks are respectively $1.47 \pm 0.11$ and $1.42 \pm 0.21$, not significantly different. The variances in both the 


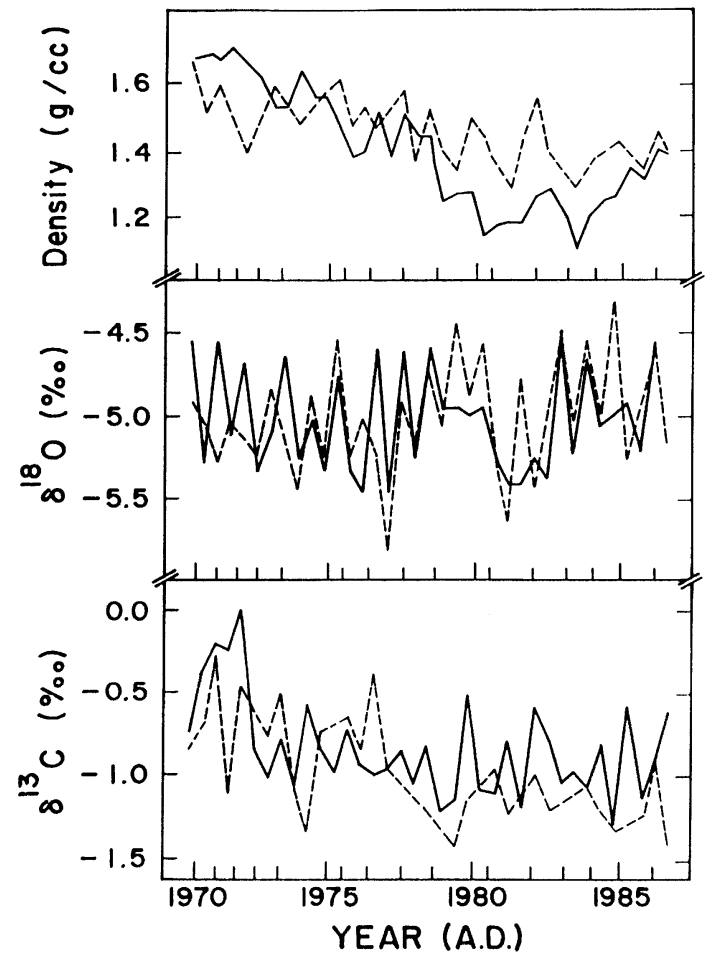

Figure $6 . \quad \delta^{18} \mathrm{O}, \delta^{13} \mathrm{C}$ and density of the two tracks plotted by choosing the data from both tracks that formed approximately at the same time (solid line, track 1 and dashed line, track 2).

isotope ratios in both the tracks are remarkably similar. It is clear that the effect of intra band isotopic variability on the proxy-SST time series is small when the sampling is done within $\pm 20^{\circ}$ of the central growth axis.

Figure 6 shows that the long term trends in $\delta^{18} \mathrm{O}$, $\delta^{13} \mathrm{C}$ and the density are similar along the two tracks, even though the absolute values do not always coincide. The annual range of temperature in this region is $4.5 \pm 1.3^{\circ} \mathrm{C}$ (Pickard et al 1977). This corresponds to a range of $\delta^{18} \mathrm{O}$ about $0.9 \pm 0.27 \%$ (neglecting the effect of salinity). This is in agreement with the observed amplitude of $\sim 0.7 \pm 0.2 \%$, within uncertainties. While this confirms that we have not missed the seasonal maxima and minima during sampling, some effect of reduced sampling size per band could result in a lesser range than expected (for details see Chakraborty and Ramesh 1998). As high density points in general show minima in $\delta^{18} \mathrm{O}$ (and low density, maxima in $\delta^{18} \mathrm{O}$ ) we infer that in this region Porites lutea generally accretes high density bands in summer and low density bands in winter. This is in agreement with Lough and Barnes (1992), who made a detailed investigation on this aspect using fluorescent bands produced in Porites due to flood discharge and concluded that in this region, high density bands form during summer.

To find the common variance between the time series of density, $\delta^{18} \mathrm{O}$ and $\delta^{13} \mathrm{C}$ between the two tracks we performed the analysis of variance as outlined by
Fritts (1976) for tree rings. In this procedure the total variance in the data set (including data from both the tracks) is expressed as a sum of variances in tracks and among tracks. The variance which is common to both the tracks is then calculated (for details see Fritts 1976). This is approximately similar to calculating the correlation coefficients between the data of the two tracks, but is statistically a more robust measure of the common signal. These common variances between the two tracks are $67 \%, 54 \%$ and $68 \%$ respectively for $\delta^{18} \mathrm{O}, \delta^{13} \mathrm{C}$ and density. This suggests that the intra-band variability introduces about $33 \%, 46 \%$ and $32 \%$ noise in the $\delta^{18} \mathrm{O}, \delta^{13} \mathrm{C}$ and density signals. Understandably, $\delta^{13} \mathrm{C}$ is controlled by varying growth rates (to be discussed later) and more prone to intra-band variability due to minor variations in the growth rates along different tracks.

Part of the noise could be an experimental artifact. That is, we have assumed that the pair of samples in the same annual bands, along the two tracks, were precipitated during the same time. In practice, it is difficult to confirm this assumption, and errors could be introduced if the samples precipitated a few weeks apart. Each sample taken for analysis will average about 3-4 weeks of growth. This problem will be accentuated when samples are taken from narrow bands $(0.5 \mathrm{~cm})$ and when the samples represent seasonal transition zones like winter to summer. Secondly, there could be genuine differences in the isotopic ratios as demonstrated by McConnaughey (1989), who showed a progressive enrichment in $\delta^{13} \mathrm{C}$ of the portion of a Porites coral growing at a lower rate due to the deficiency of sunlight. Our results indicate that the coral isotope ratio time series is not significantly affected by the intra-band isotope variability, as long as the sampling track is not more than $20^{\circ}$ off the central growth axis.

Table 1 shows the linear correlation coefficients between $\delta^{18} \mathrm{O}$ and density, $\delta^{13} \mathrm{C}$ and density, $\delta^{18} \mathrm{O}$ and $\delta^{13} \mathrm{C}$ for the two tracks, calculated from the measured time series without any detrending. There are long

Table 1. Linear correlation coefficients between $\delta^{18} O, \delta^{13} C$ and density.

\begin{tabular}{lcc}
\hline & \multicolumn{2}{c}{ Linear correlation coefficient } \\
\cline { 2 - 3 } & Actual data & Detrended data \\
\hline$\delta^{18} \mathrm{O}$ and Density & 0.23 & 0.29 \\
Track 1 & 0.36 & 0.18 \\
Track 2 & & \\
$\delta^{3} \mathrm{C}$ and Density & 0.56 & 0.20 \\
Track 1 & 0.54 & 0.17 \\
Track 2 & & \\
$\delta^{18} \mathrm{O}$ and $\delta^{13} \mathrm{C}$ & 0.02 & 0.04 \\
Track 1 & 0.28 & 0.31 \\
Track 2 & & \\
\hline
\end{tabular}

To be significant at $0.5 \%$ level the correlation coefficient should be greater than 0.36 
term trends in the records as shown by smooth lines in figures 4 and 5 . As correlations between any two time series could be either due to seasonal variations or due to long term trend, or both, it is necessary to check the correlations after detrending the data. Therefore, the linear correlation coefficients are shown for the detrended data as well (the detrending was done by subtracting calculated values from the fourth order polynomial fit, from the observed data). There is no significant correlation between $\delta^{18} \mathrm{O}$ and density in either track, before or after detrending (table 1), suggesting that the density band variations are probably not directly controlled by SST variations. However, there is a significant correlation between $\delta^{13} \mathrm{C}$ and density in each track before the data are detrended. This implies that the density band formation takes place due to the changes in the growth rate rather than SST. This correlation becomes insignificant when the data are detrended, probably implying that long term density variations are influenced by endogenic rather than exogenic factors (e.g. long term changes in light and hence growth rates).

The coral density decreases with time in both the tracks (figures 4 and 5). The magnitude of decrease is about $0.25 \mathrm{~g} / \mathrm{cm}^{3}$ for track- 1 and $0.5 \mathrm{~g} / \mathrm{cm}^{3}$ for track- 2 between 1968 and 1984 A.D. The reduction in density is more pronounced in the track which is farther away from the central growth axis. The $\delta^{13} \mathrm{C}$ also decreases by $0.5 \%$ in both the tracks during this period. The positive correlation between $\delta^{13} \mathrm{C}$ and density in each of these tracks, therefore, arises due to the long term trend in the data. Slower growth rate corresponds to higher density during 1968-74, the early part of the record, as seen in figures 4 and 5 . The later part of the record shows higher growth rates and lower densities in general. As shown by McConnaughey (1989), the $\delta^{13} \mathrm{C}$ values in years of slow growth are isotopically enriched compared to those of years of higher growth rate. Therefore we infer that the density banding is more likely to be determined by variation in growth rate rather than by variation in SST. This is to some extent corroborated by the fact that $\delta^{18} \mathrm{O}$ and $\delta^{13} \mathrm{C}$ are not correlated. If the kinetic effects were dominant during the incorporation of the isotopes from the sea water to the coral skeleton, one would observe a strong positive correlation between the $\delta^{18} \mathrm{O}$ and $\delta^{13} \mathrm{C}$ (McConnaughey 1989). The absence of such a correlation also indicates that metabolic (growth related) fractionation is dominant in the case of $\delta^{13} \mathrm{C}$.

\section{Conclusions}

Density, $\delta^{18} \mathrm{O}$ and $\delta^{13} \mathrm{C}$ time series obtained from two tracks of a Porites coral, one close to the central growth axis and another $20^{\circ}$ off the axis indicate that there is a small but systematic intraband variability across the central growth axis. Oxygen isotope ratio shows significant correlation with SST in both the tracks. The carbon isotopic composition seems to be largely controlled by intrinsic factors like metabolism and the variable growth rate. The correlation between density and $\delta^{13} \mathrm{C}$ implies that the density band formation is controlled possibly by variable growth rate rather than SST.

\section{Acknowledgements}

The study was supported by the Indian National Science Academy and the Geosphere Biosphere Programme of Indian Space Research Organization. We are thankful to S Krishnaswami for discussion and two anonymous reviewers for comments.

\section{References}

Aharon P 1991 Recorders of reef environment histories: stable isotopes in corals giant clams and calcareous algae; Coral Reefs 10 71-90

Barnes D J and Lough J M 1989 The nature of skeletal density banding in scleractinian corals: fine banding and seasonal patterns; J. Exp. Mar. Biol. Ecol. 126 119-134

Buddemeier R W 1974 Environmental controls over annual and lunar monthly cycles in hermatypic coral calcification; Proc. Second Int. Coral Reef Symp. Great Barrier Reef Committee, Brisbane 259-267

Chakraborty S and Ramesh R 1992 Monsoon induced sea surface temperature changes recorded in Indian corals; In; Oceanography of the Indian Ocean (ed) B N Desai (New Delhi, Oxford \& IBH) pp. 473-478

Chakraborty S and Ramesh R 1993 Monsoon induced sea surface temperature changes recorded in Indian coral; Terra Nova 5 546-551

Chakraborty S and Ramesh R 1997 Environmental significance of carbon and oxygen isotope ratios of banded corals from Lakshadweep India; Quaternary International 37 55-65

Chakraborty S and Ramesh R 1998 Stable isotope variations in a coral from the Gulf of Kutch: environmental implications; Proc. Indian. Acad. Sci. (Earth Planet. Sci.) (Special volume on Isotopes in the Solar System) 107 331-341

Charles C D, Hunter D E and Fairbanks R G 1997 Interaction between the ENSO and the Asian monsoon in a coral record of tropical climate; Science 277 925-928

Chivas A R, Aharon P, Chappell J, Vlaustuin C and Kiss E 1983 Trace elements and stable isotope ratios of annual growth bands as environmental indicators; Proc. Inaugural Great Barrier Reef Conference (Townsville JCU Press) 77-81

Craig H and Gordon L I 1965 Deuterium and oxygen 18 variations in the ocean and the marine atmosphere; In; Stable Isotopes in Oceanographic Studies and Paleotemperatures. Third SPOLETO Conference on Nuclear Geology Pisa Italy $161-181$

Cole J E and Fairbanks R G 1990 The southern oscillation recorded in the $\delta^{18} \mathrm{O}$ of corals from Tarawa atoll; Paleoceanography 5 669-683

Druffel E R M 1985 Detection of El Nino and decade time scale variations of sea surface temperature from banded coral records: implications for the carbon dioxide cycles; In: The Carbon Cycle and the Atmospheric $\mathrm{CO}_{2}:$ Natural Variations Archean to Present (eds) E T Sundquist and W S Broecker Geophys Monograph 32 (Washington DC: American Geophysical Union) pp. 111-122 
Eddy J A 1992 The PAGES project: Proposed implementation plans for research activities; IGBP Report 19

Fairbanks R G and Dodge R E 1979 Annual periodicity of the ${ }^{18} \mathrm{O} /{ }^{16} \mathrm{O}$ and ${ }^{13} \mathrm{C} /{ }^{12} \mathrm{C}$ ratios in the coral Montastrea annularis; Geochim. Cosmochim. Acta 43 1009-1020

Fritts H C 1976 Tree rings and climate (London: Academic Press)

Highsmith R C 1979 Coral growth rates and environmental control of the density banding; J. Exp. Mar. Biol. Ecol. 37 $105-125$

Hughes M K, Kelly P M, Pilcher J R and LaMarche V C Jr 1982 Climate from tree rings; Cambridge University Press

Lough J M and Barnes D J 1990 Possible relationships between environmental variables and skeletal density in a coral colony from the Central Great Barrier Reef; J. Exp. Mar. Biol. Ecol. 134 221-241

Lough J M and Barnes D J 1992 Comparisons of skeletal density variations in situ from the central G.B.R.; J. Exp. Mar. Biol. Ecol. 155 1-25

Matsumoto E 1993 Sclerochronological study on climatic and oceanographic changes; Proc. PAGES Workshop on High Resolution Records of Past Climate from Monsoon Asia: The Last 2000 Years and Beyond (Taipei, Taiwan April 2123) pp. 24-26

McConnaughey T $1989 \mathrm{C}$ and O isotopic disequilibrium in biological carbonates: I Patterns and II In vitro simulation of kinetic isotope effects; Geochim. Cosmochim. Acta 53 151-171

Patzold J 1984 Growth rhythms recorded in stable isotopes and density bands in the reef coral Porites lobata (Cebu Philippines); Coral Reefs 3 87-90
Pickard G L Donguy J Y Henin C and Rougerie F 1977 A review of the Physical Oceanography of the Great Barrier Reef and Western Coral Sea Monograph 2 (Australian Institute of Marine Science Townsville) p. 135

Quay P D, Tilbrook B and Wong C S 1992 Oceanic uptake of fossil fuel $\mathrm{CO}_{2}$ : carbon-13 evidence; Science 254 74-79

Ramesh R, Bhattacharya S K and Gopalan K 1985 Dendroclimatological implications of isotope coherence in trees from Kashmir Valley India; Nature 317 802-804

Ramesh R, Bhattacharya S K and Gopalan K 1986 Climatic correlations in the stable isotopic records of silver fir (Abies pindrow) trees from Kashmir India; Earth. Planet. Sci. Lett. 79 66-74

Scoffin T P, Tudhope A W, Brown B E, Chansang H and Cheeny R F 1992 Patterns and possible environmental controls of skeletogenesis of Porites lutea, South Thailand; Coral Reefs 11 1--11

Weber J N and Woodhead P M J 1972 Temperature dependence of oxygen-18 concentration in reef coral carbonates; $J$. Geophys. Res. 77 463-473

Weber J N, White E W and Patricia H W 1975 Correlation of density banding in reef coral skeletons with environmental parameters: the basis for interpretation of chronological records preserved in the corolla of corals; Paleobiology 1137 149

Wellington G M and Glynn P W 1983 Environmental influences on skeletal banding in eastern Pacific (Panama) corals; Coral Reefs 1 215-222

Yapp C J and Epstein S 1982 Climatic significance of hydrogen isotope ratios in the cellulose; Nature 297 636--639 